\title{
THE RELATIVE TRANSFER OF ESTROGENS AND THEIR GLUCURONIDES ACROSS THE PLACENTA IN THE GUINEA PIG ${ }^{1}$
}

\author{
By JOSEPH DANCIS, 2 WILLIAM L. MONEY, GEORGE P. CONDON, AND \\ MORTIMER LEVITZ \\ (From the Departments of Pediatrics and Obstetrics and Gynecology, New York University- \\ Bellevue Medical Center, and the Sloan-Kettering Institute for Cancer \\ Research, New York, N. Y.)
}

(Submitted for publication April 21, 1958; accepted June 19, 1958)

It has been suggested that estrogens can pass through the placenta because of their low molecular weight. This is supported by the demonstration of estriol in the urine of newborn male infants (1). However, there is no direct evidence to support the statment, nor is there information as to the nature of the estrogens that can or cannot be transferred.

Estrogens, in common with other steroids, are rapidly conjugated in vivo with glucuronic acid. This converts them into water-soluble materials, in which form they are excreted in the urine. The unconjugated estrogens appear in the urine in only trace amounts. We have used $\mathrm{C}^{14}$ labeled estradiol and estriol in pregnant guinea pigs, and studied the relative permeability of the placenta to the unconjugated estrogens, as well as their conjugated forms, particularly the glucuronides. In the course of the investigation, it became obvious that the customary approach to the study of placental permeability may be misleading particularly when dealing with rapidly metabolized materials, unless the effects of fetal and maternal metabolism and of placental permeability are carefully differentiated. By using a technique which excludes fetal metabolism, clearly definable results were obtained. This was accomplished at hysterotomy by clamping the umbilical cord close to the fetus and perfusing the fetal side of the placenta.

1 The investigation was supported in part by Research Grants PHS-G-4024 from the National Institutes of Health, Public Health Service; PHS-C-2071 from the National Cancer Institute, Public Health Service; the Association for the Aid of Crippled Children; and the American Cancer Society.

2 John and Mary Markle Scholar in Medical Science.

\section{METHODS}

A perfusion technique similar to one previously used in sheep (2) was adapted to the guinea pig. The fetus was delivered by hysterotomy into a saline bath maintained at $37^{\circ} \mathrm{C}$., and the umbilical vessels were clamped close to the fetus. The umbilical vein and an umbilical artery were cannulated, and the fetal side of the placenta was perfused with guinea pig plasma. ${ }^{3}$ The preparation then consisted of an artificial circulation on the fetal side of the placenta, while the maternal circulation was maintained intact. Since oxygen is supplied to the placenta from the maternal circulation, no attempt was made to oxygenate the perfusate nor were red blood cells added. The placenta was perfused at a rate of $2 \mathrm{ml}$. per minute. The placental blood flow in the guinea pig has been reported as $2.5 \mathrm{ml}$. per minute (3). With this experimental technique, the transfer rates of $\mathrm{Na}^{\mathbf{m}}$, $\mathrm{I}^{12 \mathrm{in}}$-antipyrine and various monosaccharides will remain constant for periods up to an hour, indicating a functioning placenta (4).

To study the transfer from mother to fetus, the estrogen dissolved in $1 \mathrm{ml}$. of plasma was injected into the maternal jugular vein and its appearance in the perfusate was noted. For fetal to maternal transfer, the estrogen was added to the perfusate, and its disappearance during two cycles of $12 \mathrm{ml}$ : of perfusate was followed. In both instances the estrogen was dissolved in $0.1 \mathrm{ml}$. ethanol before adding to plasma.

Preparation of radioactive materials. Estradiol-16-C $\mathrm{C}^{\text {14 }}$ (5) and estriol-16-C16 (6) were synthesized in our laboratories. The radioactive impurities as indicated by chromatography on paper were about 2 per cent. The specific activity of the estradiol-17 $\beta$-16-C ${ }^{14}$ was $9.5 \times 10^{\circ}$ counts per minute (cpm) per mg., and of the estriol-16- $\mathrm{C}^{14}, 7.0 \times 10^{\circ}$ (cpm) per mg. Estriol-16-C $\mathrm{C}^{\text {16 }}$ was syntheszied with high specific activity $\left(3.0 \times 10^{7} \mathrm{cpm}\right.$ per mg.) for use in Experiment 4, Table I and Experiment 3, Table II.

The glucuronides were prepared biosynthetically. The common bile duct of a guinea pig was ligated to eliminate the metabolism of the steroid that may occur through the entero-hepatic circulation. One mg. of estradiol-16$\mathrm{C}^{14}$ was injected intraperitoneally and the urine was collected for 24 hours. The urine was extracted with

${ }^{3}$ The guinea pig plasma was diluted with two parts of normal saline in order to conserve plasma. 
TABLE I

Maternal to fetal transfer of estrogens and metabolites

\begin{tabular}{|c|c|c|c|c|c|c|}
\hline \multirow[b]{2}{*}{ Injected estrogen* } & \multirow[b]{2}{*}{$\begin{array}{l}\text { Injected } \\
\text { radioactivity }\end{array}$} & \multirow[b]{2}{*}{ Time } & \multicolumn{2}{|c|}{ Maternal radioactivity } & \multicolumn{2}{|c|}{ Perfusate radioactivity } \\
\hline & & & $\begin{array}{c}\text { Ether } \\
\text { soluble }\end{array}$ & $\begin{array}{c}\text { Water } \\
\text { soluble }\end{array}$ & $\begin{array}{l}\text { Ether } \\
\text { soluble }\end{array}$ & $\begin{array}{l}\text { Water } \\
\text { soluble }\end{array}$ \\
\hline Free & total cpm & $\min$. & \multicolumn{2}{|c|}{ cpm/ml. plasma } & \multicolumn{2}{|c|}{ total cpm from 0-6 minutest } \\
\hline 1. Estradiol & $1.9 \times 10^{8}$ & $\begin{array}{l}1 \\
6\end{array}$ & $\begin{array}{r}1,050 \\
142\end{array}$ & $\begin{array}{l}585 \\
459\end{array}$ & 1,594 & 1,513 \\
\hline 2. Estradiol & $2.1 \times 10^{8}$ & $\begin{array}{l}1 \\
6\end{array}$ & $\begin{array}{r}6,635 \\
861\end{array}$ & $\begin{array}{l}975 \\
993\end{array}$ & 4,358 & 1,719 \\
\hline 3. Estriol & $1.8 \times 10^{6}$ & $\begin{array}{l}1 \\
6\end{array}$ & $\begin{array}{l}2,800 \\
1,420\end{array}$ & $\begin{array}{r}650 \\
1,200\end{array}$ & 1,664 & 1,018 \\
\hline 4. Estriol & $6.0 \times 10^{7}$ & 20 & 15,400 & 40,300 & 4,600 & 950 \\
\hline \multicolumn{7}{|l|}{ Conjugates } \\
\hline 5. Estradiol & $4.3 \times 10^{5}$ & $\begin{array}{l}1 \\
6\end{array}$ & ${ }_{4 \dagger}^{14}$ & $\begin{array}{r}3,600 \\
490\end{array}$ & 4 & 368 \\
\hline 6. Estradiol & $4.9 \times 10^{5}$ & $\begin{array}{l}1 \\
6\end{array}$ & $\begin{array}{r}147 \\
15\end{array}$ & $\begin{array}{l}5,440 \\
1,210\end{array}$ & 118 & 84 \\
\hline 7. Estriol & $1.3 \times 10^{6}$ & $\begin{array}{l}3 \\
8\end{array}$ & $\begin{array}{l}758 \\
834\end{array}$ & $\begin{array}{l}16,800 \\
13,670\end{array}$ & $3 \S$ & $52 \S$ \\
\hline 8. Estriol & & 6 & 12 & 1,620 & $4 \S$ & $100 \S$ \\
\hline
\end{tabular}

* Estrogens were injected into left maternal jugular vein at " 0 " time. One minute maternal sample was taken from right jugular and six minute sample by cardiac puncture. Fetal placenta was perfused for six minutes with 12 ml. of plasma; then total radioactivity appearing in perfusate was determined.

$\dagger$ Except in Experiment 4, in which estriol-16-C ${ }^{14}$ was given in four equal doses at 0,5,10 and 15 minutes and the perfusate was collected for 20 minutes.

$\ddagger$ The injected conjugates were butanol extracts of urine of donor guinea pigs injected with radioactive estrogens and were 80 to 90 per cent glucuronides.

$\$$ Calculation based on less than $6 \mathrm{cpm}$ above background observed.

ether to remove unconjugated estrogens. The aqueous phase was adjusted to $\mathrm{pH} 2$ and extracted with butanol. The butanol was removed in vacuo and replaced with water. This solution contained 98 per cent of the urinary radioactivity. To demonstrate its composition, an aliquot was incubated with $\beta$-glucuronidase ( 500 units per ml.) 4 at $\mathrm{pH} 5$ at $37^{\circ} \mathrm{C}$ for four days (7), after which 92 per cent of the radioactivity was extractable with ether. No attempt was made to identify the individual components of the glucuronide fraction.

The estriol glucuronide was also prepared biosynthetically. The urine was extracted with butanol and 95 per cent of the radioactivity appeared in the extract. Eighty-seven per cent of the extract was hydrolyzable by $\beta$-glucuronidase. After incubation with $\beta$-glucuronidase, the urine was hand-extracted with ether at $\mathrm{pH} 5$. The ether-soluble fraction was chromatographed on silica gel (8). All the radioactivity was eluted in the estriol fraction. Analysis by isotope dilution indicated that 85 per cent of the radioactivity was present in estriol.5 Hence,

\footnotetext{
- Ketodase®, Warner-Chilcott Laboratories, N. J.

5 The authors are indebted to Parke-Davis and Company for generous gifts of estriol.
}

approximately 75 per cent of the butanol extract was estriol glucuronide.

Further confirmation of the nature of the conjugates was obtained by incubating with a $\beta$-glucuronidase inhibitor and a phenolsulfatase. A solution of the estriol conjugates containing $26,000 \mathrm{cpm}$ was divided into two equal parts after adjusting the $\mathrm{pH}$ to 5 and adding onetenth volume of acetate buffer $(\mathrm{pH} 5)$. One part received 300 units per $\mathrm{ml}$. of Ketodase. In addition to the Ketodase the second was treated with a solution of saccharic acid which had been freshly boiled at $\mathrm{pH}$ 3.5 for 30 minutes (9). The final concentration was $4.3 \times 10^{-8} \mathrm{M}$ with respect to saccharate. The solutions were incubated for 22 hours at $37^{\circ} \mathrm{C}$. Samples were extracted with ether and the radioactivities were measured. Only 6 per cent of the radioactive conjugates was hydrolyzed in the presence of the saccharic inhibitor as compared to 76 per cent in the control. Another aliquot was incubated with sulfatase ${ }^{\circ}$ (10) for 24 hours, after which time 3 per cent of the radioactivity was ex-

6 Mylase P., Wallerstein Laboratories, New York, N. Y. 
TABLE II

Disappearance of estrogens from fetal perfusate*

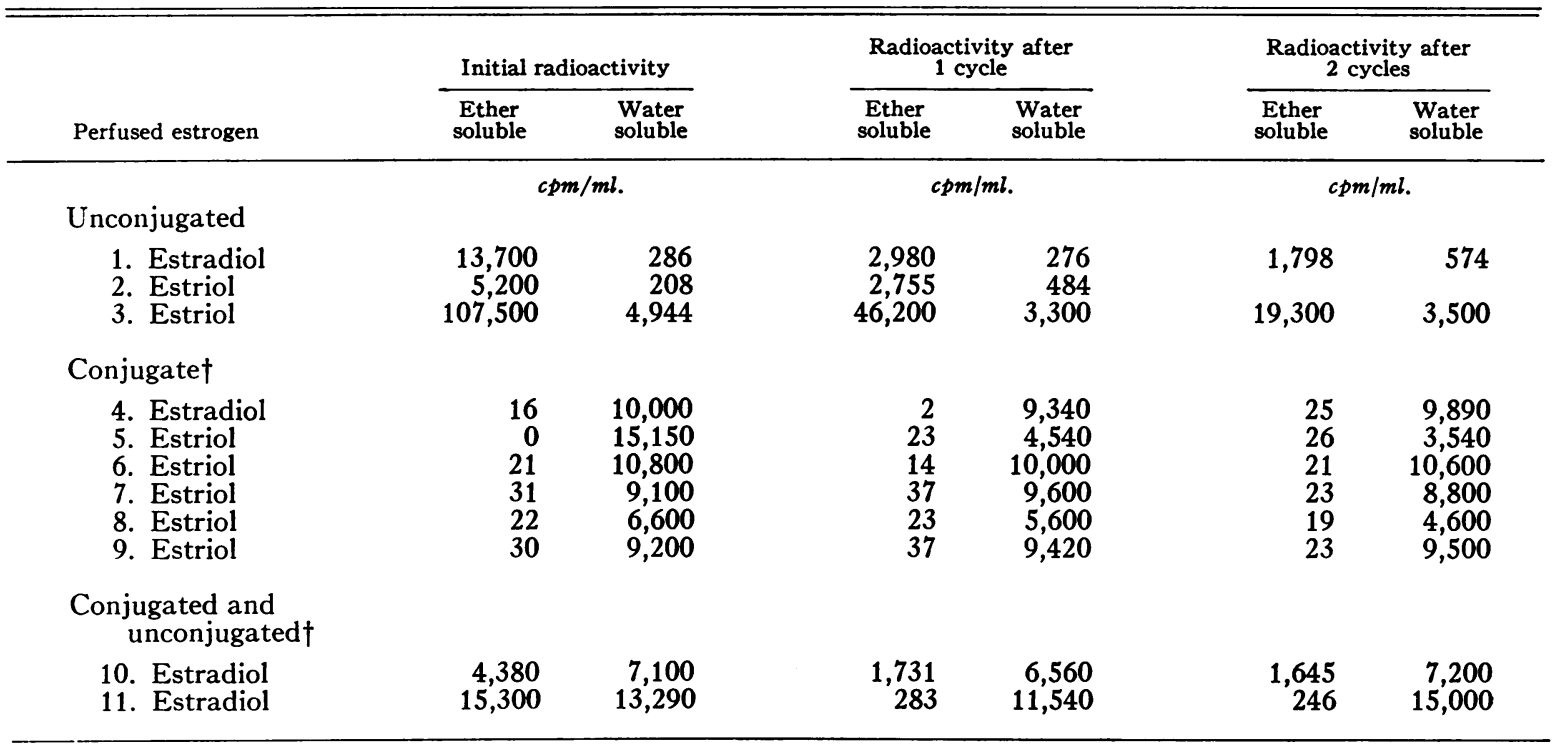

* Estrogens were added to the perfusate and samples were taken before perfusion and from the perfusion circulation (fetal side of the placenta) after 1 and 2 cycles.

$\dagger$ The injected conjugates were butanol extracts of urine of donor guinea pigs injected with radioactive estrogen and were 80 to 90 per cent glucuronides.

tracted with ether. A sample of estrone-16- $\mathrm{C}^{14}$ sulfate was quantitatively hydrolyzed under similar conditions.

Analytical techniques. After the perfusion ethanol was added to the plasma to a final concentration of 80 per cent and the mixture filtered. The protein precipitate was washed with 80 per cent ethanol and the washes were added to the filtrate. The filtrate was distilled under vacuum to near dryness and then redissolved in $10 \mathrm{ml}$. of water. This was extracted four times with $3 \mathrm{ml}$. of ether (in the estriol experiments, 20 per cent chloroform in ether was used). Samples of both phases were plated on tin-plated planchets. The radioactivity was determined in a D-46A nuclear flow gas counter and corrected to infinite thinness. The efficiency of the counter is 55 plus or minus 5 per cent.

The purity of the radioactive estrogen was determined by paper chromatography (11). Estriol was chromatographed in a solvent system of chloroform-formamide for two days and estradiol in benzene-formamide for five hours. The pattern of radioactivity was determined in a windowless automatic chromatogram scanner. ${ }^{7}$ Nonradioactive estrogens of known purity were run concurrently either on the same paper strip or on a parallel one and the color developed by Turnbull's blue reagent (12). The purity of the radioactive sample was calculated from the amount of radioactivity found in the band corresponding to the nonradioactive estrogen.

In some experiments the radioactivity remaining in the

` Purchased from Atomic Accessories Inc., Bellerose, N. Y. plactenta at the conclusion of the perfusion was determined. The placenta was extracted four times with 80 per cent ethanol in the Waring blendor. Less than 0.5 per cent of the radioactivity remained unextracted by this procedure.

\section{RESULTS}

\section{Transfer from mother to fetus}

When estradiol-C-14 was injected into the pregnant guinea pig and the fetal placenta perfused, ether-soluble materials were recovered in the perfusate (Table I). However, estradiol-C-14 could not be demonstrated in the perfusate by paper chromatography. When the experiments were repeated with estriol-C-14 unequivocal evidence of transfer of the unaltered estrogen was obtained. In Table I, Experiment 4, only one peak of radioactivity was demonstrated on paper chromatography of the ether-soluble fraction of the perfusate and this corresponded to the mobility of carrier estriol. The precipitous change in maternal blood levels of estriol that must occur while the placenta is being perfused does not permit any precise interpretation of the rate of transfer, but it is evident that transfer is rapid.

Following the injection of estriol into the 
mother, the water-soluble radioactivity recovered in the perfusate was not hydrolyzable by $\beta$-glucuronidase. However, the enzyme did hydrolyze about 50 per cent of the water-soluble radioactivity found in the maternal blood at the end of the experiment. Similar observations were made with estradiol. The findings suggested placental permeability to some estrogen conjugates but not to glucuronides. This impression concerning the glucuronides was confirmed by injecting biosynthetically prepared glucuronide into the mother (Table I). Very little radioactivity was recovered in the placental perfusate. The nature of the conjugates to which the placenta is permeable is under investigation.

\section{Transfer from fetus to mother}

In the investigation of transfer across the placenta from fetus to mother, the radioactive estrogens were added to the perfusate and the disappearance of radioactivity after the first and second cycle was recorded. The results (Table II) clearly showed a rapid disappearance of the estrogens, a large amount during the first cycle and less in the second. In contrast, the level of glucuronides in the perfusate remained essentially unchanged after perfusion in all experiments except one.

The question arose as to whether the disappearance of radioactivity from the perfusate did, in fact, indicate transfer across the placenta. To demonstrate this, estriol with high specific activity was perfused through the placenta (Table II, Experiment 3 ) after which it was possible to identify estriol-C-14 in the maternal blood by paper chromatography. It would be expected that the estrogens transferred to the mother would rapidly disappear from the maternal circulation (13) so that no quantitative interpretation of transfer can be made from the amount recovered in the maternal plasma. However, indirect evidence indicates that the disappearance of radioactivity from the perfusate is primarily the result of transfer. Storage of estrogens in the placenta during the course of the perfusion was excluded by determining the radioactivity in the placenta. In Table II, Experiment 3 , a total of $1.9 \times 10^{8} \mathrm{cpm}$ of estriol-C-14 was added to the perfusate. At the end of two cycles the entire placenta contained only 75,000 cpm. This represents only 5 per cent of the $1.5 \times$ $10^{6} \mathrm{cpm}$ that disappeared from the perfusate. However, the accumulation of estriol that did occur in the placenta during the perfusion reduced the gradient from the perfusate and may be responsible for the reduced rate of disappearance of estrogens during the second cycle.

The ether-soluble radioactivity remaining in the perfusate at the end of Experiment 3 (Table II) was still estriol, indicating that the placenta did not significantly metabolize this estrogen in the course of the experiment.

It would appear from the foregoing that a quantitative estimate of transfer can be made from the disappearance of radioactivity from the perfusate, and that it is very rapid.

It may be noted that roughly 5 per cent of the radioactivity in the perfusate in the first three experiments in Table II is water-soluble before perfusion. This is puzzling because less than 1 per cent of the radioactivity added to the perfusate was water-soluble. We have no explanation and do not know if it is an artifact of the analytical procedure or the result of interaction with the plasma. However, it does not affect interpretation of the results.

\section{DISCUSSION}

Our first attempts to study the transfer of estrogens across the placenta were done in what might be considered the orthodox manner. EstradiolC-14 was injected intravenously into the pregnant guinea pig and because of the extremely rapid disappearance of radioactivity from the maternal blood stream, maternal and fetal blood samples were taken one minute later. The relatively large amount of water-soluble radioactivity in the fetal plasma suggested a preferential transfer of the conjugates across the placenta. However, we subsequently found that the fetus could also rapidly convert estradiol into water-soluble materials producing the erroneous impression of preferential permeability. It became evident that a technique must be used that would make it possible to separate the effects of fetal metabolism from placental transfer.

When the complicating feature of fetal metabolism was removed by replacing the fetal circulation with a perfusion system, all suggestion of preferential transfer of the conjugates disappeared. 
Although maternal metabolism still limited the quantitative interpretation of the data, it was possible to demonstrate rapid transfer of estriol-C-14 in both directions. Estriol has not been demonstrated to be a normal product of guinea pig metabolism, but it proved to be useful in our studies. We were unable to demonstrate the transfer of estradiol probably because estradiol is rapidly metabolized and less radioactivity was used than in the estriol experiments. However the ethersoluble metabolites of estradiol move rapidly across the placenta in both directions.

Following the intravenous injection of radioactive estrogens into the mother, the radioactivity disappears extremely rapidly from the plasma (Table I). Less than 7,500 cpm per ml. could be detected in the maternal plasma one minute after the injection of approximately two million counts per minute into the maternal jugular vein. This cannot be explained by simple equilibration within body fluids and at present is unexplained. A similar experience has been reported in humans (13). The rapid disappearance of injected radioactivity from the maternal circulation is probably largely responsible for the fact that less than 1 per cent reaches the fetal circulation. It also prevents any precise estimate of the rate of transfer of these materials across the placenta from mother to fetus.

The experiments on transfer from fetus to mother were not complicated by a rapidly falling estrogen level. The radioactivity in the perfusate entering the placenta was maintained at a constant level and it is evident that a considerable amount of the unconjugated estrogens disappeared during the first cycle (Table II). Since only an insignificant amount was recovered in the placenta at the end of the experiment it can be assumed that the rest was transferred across the placenta. The greatly reduced transfer on the second cycle may be the result of a reduced gradient produced by the small retention of estrogens in the placenta.

These results contrast sharply with those with the glucuronide conjugates, little or none of the latter being transferred across the placenta in either direction. It has been reported that the fetal guinea pig does not form glucuronides effectively (14). This may represent a significant advantage in the disposal of materials in utero since the placenta is relatively impermeable to the glucuronides. Once the ether-soluble estrogens are transfererd to the maternal circulation, conjugation and renal excretion by the mother would follow.

Estrogens are transported in the plasma bound to proteins. To make certain that the estrogens in the perfusion experiments were protein-bound, in one experiment estradiol-C-14 was solubilized in plasma diluted with saline as usual and then dialyzed against saline for 72 hours at $4^{\circ} \mathrm{C}$. At the end of this time, 97 per cent of the radioactivity was still retained in the cellophane bag. ${ }^{8}$ When this material was perfused through the fetal placenta the results resembled those presented in Table II. In the solution prior to perfusion there were $9,130 \mathrm{cpm}$ per ml., which dropped to 3,070 after one cycle and 2,170 after the second.

Protein-bound estrogens exchange very slowly across inert membranes (15). Since plasma proteins exchange slowly between mother and fetus (16), the very rapid transfer of estrogens across the placenta suggests a mechanism for rapidly releasing the protein-binding at the placental membrane. The investigations of physiologists suggest a possible explanation (17). It has been demonstrated that a major factor determining rate of transport is the oil to water partition of the substance under study-the more lipid-soluble, the more rapidly transported. From this, it has been deduced that a large portion of the membrane area is lipid in character. Water-soluble materials must travel through the relatively sparsely situated water-filled pores, the molecular size of the material being a major controlling factor in the rate of transport. In applying this theory to our observations, one may suspect that the greater solubility of the unconjugated estrogens in lipids could lead to extraction from the circulating fetal plasma by the placental membrane. The extraction of the unbound, unconjugated estrogens from the plasma could displace the equilibrium and rapidly release more estrogens from their protein-binding. Alternatively, the placental membrane may compete favorably with the plasma proteins for the bound estrogens. Partition of the extracted lipids could then take place with

\footnotetext{
8 In a control experiment in which no plasma was placed in the dialysis bag, the radioactivity was distributed equally inside and outside the bag within 24 hours.
} 
the estrogen-poor maternal plasma on the other side of the membrane. This mechanism would not be available to the water-soluble glucuronide.

At first glance, the rapid transfer of ether-soluble estrogens and the relative impermeability of the glucuronides through the placenta are difficult to reconcile with the performance of the kidney where the glucuronide is preferentially excreted. The difference in structure between the two organs suggest explanations, a detailed consideration of which is outside the scope of this paper.

\section{SUMMARY}

The transport of estrogens across the placenta was studied using the following technique: The guinea pig fetus was removed by hysterotomy and the fetal placenta perfused in situ leaving the maternal circulation intact. This eliminated the complicating feature of fetal metabolism. With this technique it was possible to demonstrate the rapid transfer of estriol-16-C ${ }^{14}$ and the ether-soluble metabolites of estradiol-16- $\mathrm{C}^{14}$ across the placenta in both directions. However, the placenta was relatively impermeable to the water-soluble estrogens found in urine, 80 to 90 per cent of which are glucuronides. The possible significance of protein-binding and of glucuronide conjugation in transport and excretion is briefly discussed.

\section{REFERENCES}

1. Diczfalusy, E., Tillinger, K. G., and Westman, A. Studies on oestrogen metabolism in newborn boys. I. Excretion of oestrone, oestradiol-17 $\beta$ and oestriol during the first few days of life. Acta endocr. (Kbh.) 1957, 26, 303.

2. Alexander, D. P., Huggett, A. St. G., Nixon, D. A., and Widdas, W. F. The placental transfer of sugars in the sheep: The influence of concentration gradient upon the rates of hexose formation as shown in umbilical perfusion of the placenta. J. Physiol. 1955, 129, 367.
3. Huggett, A. St.G. Growth, pregnancy, and carbohydrate metabolism. Amer. J. Obstet. Gynec. 1955, 69, 1103.

4. Dancis, J., and Money, W. L. Unpublished observations.

5. Levitz, M. The synthesis of $17 \beta$-estradiol-16- $C^{14}$. J. Amer. chem. Soc. 1953, 75, 5352.

6. Levitz, M., Spitzer, J. R., and Twombly, G. H. Interconversions of 16-oxygenated estrogens: $\mathrm{I}$. The synthesis of estriol-16-C $\mathrm{C}^{14}$ and its metabolism in man. J. biol. Chem. 1958, 231, 787.

7. Beer, C. T., and Gallagher, T. F. Excretion of estrogen metabolites by humans. I. The fate of small doses of estrone and estradiol-17 $\beta$. J. biol. Chem. 1955, 214, 335.

8. Levitz, M., Condon, G. P., and Dancis, J. The interconversion of estrone and estradiol in the perfused human placenta. Endocrinology 1956, 58, 376.

9. Levvy, G. A. The preparation and properties of $\beta$-glucuronidase. 4 . Inhibition by sugar acids and their lactones. Biochem. J. 1952, 52, 464.

10. Cohen, H., and Bates, R. W. Hydrolysis of conjugated sulfates of estrogens by commercial enzyme preparation of aspergillus oryzae. Endocrinology 1949, 44, 317.

11. Levitz, M., Spitzer, J. R., and Twombly, G. H. The conversion of estradiol-17 $\beta-16-C^{14}$ to radioactive 16-ketoestradiol-17 $\beta$ in man. J. biol. Chem. 1956, 222, 981.

12. Barton, G. M., Evans, R. S., and Gardiner, J. A. F. Paper chromatography of phenolic substances. Nature (Lond.) 1952, 170, 249.

13. Sandberg, A. A., and Slaunwhite, W. R., Jr. Studies on phenolic steroids in human subjects. II. The metabolic fate and hepato-biliary-enteric circulation of $\mathrm{C}^{14}$-estrone and $\mathrm{C}^{14}$-estradiol in women. J. clin. Invest. 1957, 36, 1266.

14. Brown, A. K., and Zuelzer, W. W. Studies on the neonatal development of the glucuronide conjugating system. J. clin. Invest. 1958, 37, 332.

15. Bischoff, F., and Stauffer, R. D. Orientation of circulating human estrogens by albumin. Amer. J. Physiol. 1957, 191, 313.

16. Dancis, J., and Shafran, M. The origin of plasma proteins in the guinea pig fetus. J. clin. Invest. 1958, 37, 1093.

17. Pappenheimer, J. R. Passage of molecules through capillary walls. Physiol. Rev. 1953, 33, 387. 